\title{
Bigger mothers $=$ better chances: the first test of a central hypothesis in marine fish ecology-editorial comment on the feature article by Saenz-Agudelo et al.
}

\author{
Myron A. Peck
}

Received: 13 October 2014 / Accepted: 27 October 2014 / Published online: 9 November 2014

(C) Springer-Verlag Berlin Heidelberg 2014

A major hypothesis (and assumption) of marine population ecology and marine fisheries management is that the size of female fish is positively related to the number of eggs produced and, consequently, to the number of survivors (recruits) they produce. Although the investment of energy into reproduction often increases within increasing size (larger individuals have higher fecundity than smaller individuals in marine fish species), the benefits of obtaining a large size in terms of recruitment have been notoriously difficult to document. Similarly, older females (who tend to be larger) can produce offspring with far better performance than younger females (Berkeley et al. 2004). This central hypothesis coined by some more casually as the 'Big Old Fat Fecund Female Fish (BOFFFF) Hypothesis' (Field et al. 2008; Hixon et al. 2014) has remained, essentially, untested because of the challenges associated with tracing recruits back to their parents in large enough quantities to

Communicated by U. Sommer.

M. A. Peck $(\square)$

Center for Earth System Research and Sustainability, Institute of Hydrobiology and Fisheries Science, University of Hamburg, Olbersweg 24, 22767 Hamburg, Germany

e-mail: myron.peck@uni-hamburg.de allow statistical inference. In this volume, Saenz-Agudelo et al. (2014) set out to test the BOFFFF hypothesis using a field study of the saddleback clownfish (Amphiprion polymnus) in Bootless Bay, Papua New Guinea. In this region for this species, previous research found strong connectivity among subpopulations across several sites (SaenzAgudelo et al. 2011), offering a unique chance to examine the contribution of females size to recruitment success in a metapopulation.

Saenz-Agudelo and colleagues studied 155 groups of $A$. polymnus, each group inhabiting a different anemone (Fig. 1), in seven populations (aggregations), within the bay's metapopulation. A total of 79 breeding pairs was used to disentangle which factors most influenced the number of eggs produced, and 58 breeding pairs were used to investigate the factors affecting recruitment. Looking across one life history transition (from adults to eggs), the results suggested that female size was a significant predictor of the number of eggs produced and, importantly, that the number of eggs produced was a significant predictor of the number of recruits. Looking across two life history transitions, a much more challenging task since multiple interacting factors may influence each life history transition, results suggested that female size and/or mate replacement were significant predictors of the probability of producing at least one recruit and that there were no significant predictors of the number of recruits produced. Although female size normally correlates highly with fecundity and the total number of eggs produced, the result that this higher egg production is correlated with the production of recruits provides the first support for the idea that female size is correlated with recruit production in a marine metapopulation. This study represents the first rigorous test of one of the central hypothesis of marine fish population ecology. 


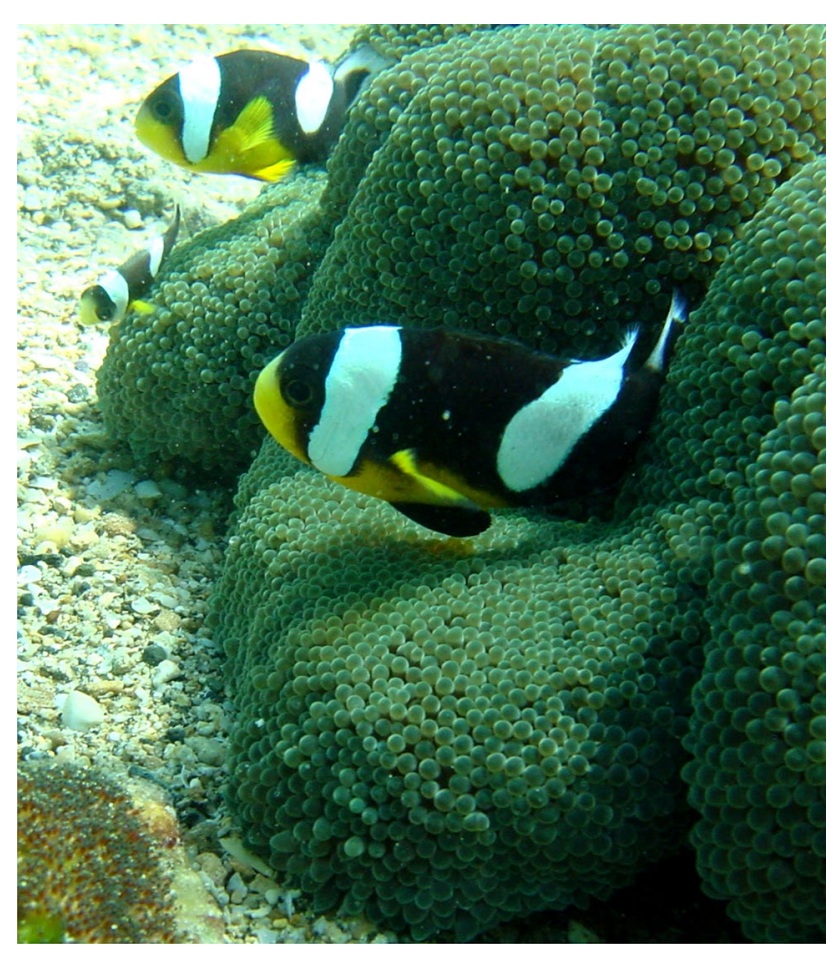

Fig. 1 A mating pair of saddleback clownfish (Amphiprion polymnus) and a smaller, subadult/juvenile at a nest location in Bootless Bay, Papua New Guinea. Photograph by Serge Planes

\section{References}

Berkeley SA, Chapman C, Sogard SM (2004) Maternal age as a determinant of larval growth and survival in a marine fish, Sebastes melanops. Ecology 85:1258-1264

Field JG, Moloney CL, du Buisson L, Jarre A, Stroemme T, Lipinksi MR, Kainge P (2008). Exploring the BOFFFF hypothesis using a model of southern African deepwater hake (Merluccius paradoxus). In: Tsukamoto K, Kawamura T, Takeuchi T, Beard TTD Jr, Kaiser MJ (eds) Fisheries for global welfare and environment. 5th World Fisheries Congress 2008, pp 17-26

Hixon MA, Johnson DW, Sogard SM (2014) BOFFFFs: on the importance of conserving old-growth age structure in fishery populations. ICES J Mar Sci 71(8):2171-2185

Saenz-Agudelo P, Jones GP, Thorrold SR, Planes S (2011) Connectivity dominates larval replenishment in a coastal reef fish metapopulation. Proc R Soc B 278:2954-2961

Saenz-Agudelo P, Jones GP, Thorrold SR, Planes S (2014) Mothers matter: contribution to local replenishment is linked to female size, mate replacement and fecundity in a fish metapopulation. Mar Biol. doi:10.1007/s00227-014-2556-x 